\title{
HISTOPATHOLOGICAL DISTRIBUTION OF THE GASTROINTESTINAL TRACT LESIONS
}

Mrinalini Sing $h^{1^{*}}$, Santosh Upadhyaya Kafle ${ }^{2}$, Neeta Kafle $^{3}$, Amrita Sinha $^{4}$, Prasun Rajbhandari ${ }^{5}$

\begin{abstract}
Affiliation
1. Assistant Professor, Department of Pathology, Birat Medical College and Teaching Hospital, Nepal

2. Professor, Department of Pathology, Birat Medical College and Teaching Hospital, Nepal

3. Assistant Professor, Department of Pathology, Birat Medical College and Teaching Hospital, Nepal

4. Lecturer Department of Pathology, Birat Medical College and Teaching Hospital, Nepal

5. Intern, Birat Medical College and Teaching Hospital, Nepal
\end{abstract}

\section{ARTICLE INFO}

Received : 22 June, 2021

Accepted : 14 July, 2021

Published : 04 November 2021

(C) Authors retain copyright and grant the journal right of first publication with the work simultaneously licensed under Creative Commons Attribution License CC - BY 4.0 that allows others to share the work with an acknowledgment of the work's authorship and initial publication in this journal.

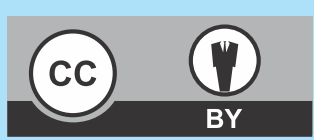

\section{ORA 264}

DOI: https://doi.org/10.3126/bjhs.v6i2.40353

\section{* Corresponding Author}

\section{Dr. Mrinalini Singh}

Assistant Professor

Department of Pathology

Birat Medical College \& Teaching Hospital, Morang, Nepal Email: sdrmrinalini@gmail.com

ORCID: https://orcid.org/0000-0001-5482-0192

\section{Citation}

Mrinalini Singh, Santosh Upadhyaya Kafle, Neeta Kafle, Amrita Sinha, Prasun Rajbhandari. Histopathological distribution of the Gastrointestinal tract lesions. BJHS 2021;6(2)15. 1529-1534.

\section{ABSTRACT}

\section{Introduction}

Gastrointestinal (GI) diseases are common and can affect any portion of the gastrointestinal tract from the mouth to the anus. Diseases can just show clinical conditions like stomach pain, constipation, diarrhea which can be selflimiting. But sometimes disease may be life-threatening like malignancy. Biopsy is necessary for confirmatory diagnosis and further treatment of the patient. So histopathologic examination should be done for all surgical procedures for confirmation and categorization of GI disorders.

\section{Objectives}

This study was done to find out the various patterns of lesions of the gastrointestinal tract with its commonest age group and sex involvement

\section{Methodology}

This was a prospective study of all the surgically resected GI tissue received in the Department of Pathology Histopathology unit in Birat Medical College and Teaching Hospital (BMCTH) from $1^{\text {st }}$ February 2021 to $30^{\text {th }}$ April 2021. The hematoxylin and eosin stain slides of the GI tissue received were studied and the lesions were diagnosed on their histomorphology. According to organ, age and sex, the lesions were categorized. The data were entered in Microsoft excel and the percentage value was calculated.

\section{Result}

Out of the total 344 cases 146 (42.44\%) were male and 198 $(57.56 \%)$ were female patients. The most common age range for $\mathrm{Gl}$ lesions was 41 to 60 years comprising of $126(36.62 \%)$ of total cases. Maximum numbers of cases 160 $(46.50 \%)$ were of cholecystectomies followed by appendectomies 95(27.60\%). Inflammatory and benign lesions comprised 332(96.51\%), 9(2.61\%) were malignant tumor and $3(0.88 \%)$ were premalignant lesions. The most common inflammatory lesions and malignant tumors were chronic cholecystitis and gastric adenocarcinoma respectively

\section{Conclusions}

The study identifies that gastrointestinal lesions comprise of the most common biopsies received in the histopathology department. Early diagnosis of premalignant and malignant lesions can improve the overall survival rate of patients.

\section{KEYWORDS}

Adenocarcinoma, Chronic cholecystitis, Gastrointestinal disease. 


\section{INTRODUCTION}

The Gastrointestinal tract (GIT) starts from the oral cavity. The hollow organs of the GIT include the oral cavity, esophagus, stomach, duodenum, jejunum, ileum, caecum, colon, rectum and anus. The Appendix is a small blind ended tubular organ connected to the caecum. The pancreas, gallbladder and liver comprise the solid organs of the digestive tract. Because of its large surface area lesions of GIT are common. ${ }^{1}$ The various biopsies from the GIT include cholecystectomies, appendicectomies, colonoscopy biopsies from colonic and rectal mucosa and endoscopic biopsies from oesophagus, duodenal and gastric mucosa. Other biopsies sites are from lesions of the oral cavity, surgical tissues or resected specimens from the pancreas, liver, esophagus, pharynx, small and large bowel along with patient may remain asymptomatic for many years or may present with non -specific signs and symptoms like abdominal pain, diarrhea, constipation, nausea, weight loss and jaundice. Many of the clinical symptoms like repeated chronic pain in abdomen, abdominal discomfort, dyspepsia, constipation or repeated attacks of diarrhea and feeling like nausea can affect the quality of life of patients. All these symptoms are present because of some pathology in the gastrointestinal tract. Since many of the GIT lesions present with similar signs and symptoms, it becomes difficult to diagnose them clinically. ${ }^{2}$ For confirmatory diagnosis of gastrointestinal lesions histopathological examination is needed. Lesions like gallstone disease, chronic gastritis, and acute appendicitis are very commonly encountered in the Nepalese population. Though many diagnostic modalities are used for diagnosing GIT lesions like ultrasonography, endoscopy, colonoscopy, endoscopic retrograde cholangiopancreatography (ERCP) and Magnetic resonance cholangiopancreatography (MRCP) but still histopathology remains the gold standard for confirmatory diagnosis. ${ }^{3}$ Most of the lesions are inflammatory and benign but some can be cancerous which is life-threatening. The research data suggest that $20 \%$ of new cancer cases worldwide are of GIT and in the Nepalese population prevalence of gastric cancer is $9.3 \%$ in males and $5.7 \%$ in females. ${ }^{4}$

The lesions of GIT develop with a sequence of metaplasia, dysplasia which can sometimes lead to carcinoma. So if precancerous lesions like dysplasia which have the potentiality to turn into cancer are diagnosed earlier it can help the treating physician and can improve the survival rate of the patient. Such types of precancerous lesions are found on the entire gastrointestinal tract. With the advancement of endoscopy and colonoscopy tiny $1-2 \mathrm{~mm}$ biopsies can be taken. Earlier histopathologic diagnosis especially in cases of ulcers either benign or malignant can prevent further progression of the disease. Studies have shown that surgically resected cancers that are confined to GIT mucosa show $100 \%$ five year- survival rate. ${ }^{5}$ To find out the depth of invasion histopathologic diagnosis is a must. Delay in the diagnosis can lead to a decreased survival rate of the patient. This study was therefore done to find out the various patterns and sites in GIT of inflammatory, benign and rectum and anal canal. The GIT lesions are common and the

malignant lesions with its commonest age group and sex involvement.

\section{METHODOLOGY}

This was a prospective study done inthe Department of Pathology Histopathology unit in Birat Medical College Teaching Hospital (BMCTH). All of the surgically resected GIT tissues sent in proper fixative from $1^{\text {st }}$ February 2021 to $30^{\text {th }}$ April 2021 were included in the study. GIT samples not sent in proper fixatives were excluded from the study. The study was conducted after taking approval from the Institutional Review Committee (IRC) of BMCTH. All the surgically resected GIT tissue received in the histopathology department were routinely grossed and paraffin embedded sections were made. Microscopic examination of Hematoxylin and Eosin (H\&E) stained slides was done. Wherever necessary, special stains like ZiehINelson (ZN) stain for tuberculosis bacilli and Giemsa stain for confirmation of organism Helicobacter Pylori (H.Pylori) were done. According to organ, age and sex the lesions were categorized. The microscopic diagnoses were further reconfirmed by other pathologists in the department who all are also the coauthors of this study. The data were entered in Microsoft Excel and statistical analysis were done.

\section{RESULTS}

There were a total of 344 cases. Out of which 146(42.44\%) were male and $198(57.56 \%)$ were female. Most common age range for $\mathrm{Gl}$ lesion was 41 to 60 years comprising 126 (36.62\%) cases. Total 332(96.51\%) were inflammatory and benign lesions, 9(2.61\%) were malignant tumors and $3(0.88 \%)$ were premalignant lesions. Maximum numbers of cases were of cholecystectomies tissue. In almost all the patients cholecystectomy was done because of gallstones disease. There were a total of 160 cases of gall bladder tissue. Out of which $122(76.25 \%)$ were female and the rest $38(23.75 \%)$ were male. Most common range of age group for cholecystectomy tissue was $41-60$ years comprising of $60(37.5 \%)$ cases. (Table1). The maximum numbers of cholecystectomy specimen where of inflammatory and benign lesions. Various patterns of different types of cholecystitis where of 156 (97.50\%). There was one $(0.6 \%)$ malignant tumor which was adenocarcinoma of gall bladder

Table 1: Age wise distribution of (344) GIT biopsies
\begin{tabular}{|l|c|c|c|c|c|}
\hline & $1-20$ & $\mathbf{2 1 - 4 0}$ & $\mathbf{4 1 - 6 0}$ & $\mathbf{6 1 - 8 0}$ & $\begin{array}{c}\mathbf{8 1} \\
\text { and } \\
\text { above }\end{array}$ \\
\hline Cholecystectomies & 2 & 53 & 60 & 42 & 3 \\
\hline Appendectomies & 41 & 30 & 20 & 4 & \\
\hline Oral biopsies & 4 & 10 & 2 & & \\
\hline Endoscopy Biopsies & & 7 & 20 & 7 & \\
\hline Colonoscopy Biopsies & 3 & 3 & 20 & 3 & \\
\hline Hepatic cyst & & & 1 & & \\
\hline Chronic Pancreatitis & & 1 & & & \\
\hline Fistula in Ano & & 2 & 1 & & \\
\hline Hemorrhoids & & 1 & 2 & & \\
\hline Rectal Carcinoma & & 1 & & & \\
\hline Submucosal lipoma & & 1 & & & \\
\hline Total & $\mathbf{5 0}$ & $\mathbf{1 0 9}$ & $\mathbf{1 2 6}$ & $\mathbf{5 6}$ & $\mathbf{3}$ \\
\hline
\end{tabular}

$\begin{array}{lll} & \text { Birat Journal of Health Sciences } \\ 15030 & \text { Vol.6/No.2/Issue 15/May-Aug., 2021 }\end{array}$




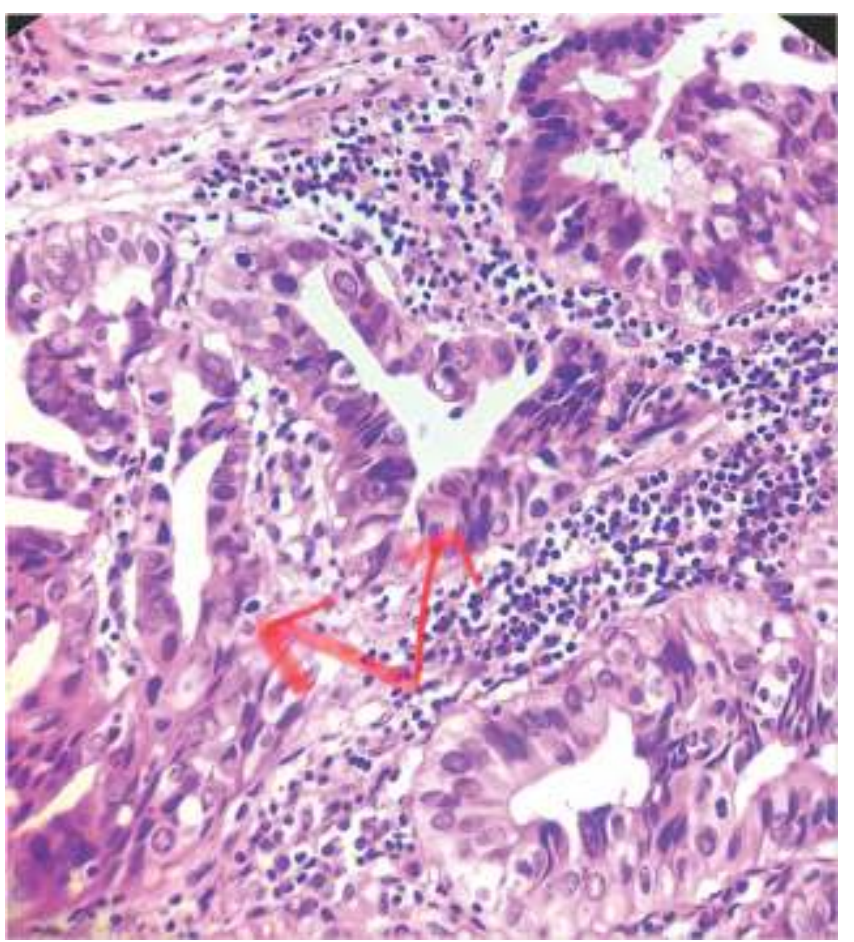

Figure 1 H\&E: Stain showing Well Differentiated Adenocarcinoma of gallbladder (40X)

(Figure 1) and three (1.9\%) premalignant lesions consisting of low-grade biliary intra epithelial neoplasia. (Table2). Total Appendix biopsies received during the study period were 95. Out of which (53.69) \%) were male and 44(46.31\%) were female patients. Acute suppurative appendicitis was the commonest diagnostic lesion. It comprised 50(52\%) of the total appendix received. (Table 3). Maximum number of appendicitis comprising of $41(43.15 \%)$ cases were seen in the younger age group 1-20 years. Total 34 endoscopy biopsies were received. Out of which $21(61.77 \%)$ were male and $13(38.23 \%)$ were female. Most of the biopsies were from the stomach comprising of 31(91\%) of total endoscopy biopsies. (Table 4). Two cases were from duodenum and one case was from oesophagus. Maximum number of cases comprising of 30 (88\%) were inflammatory and benign lesions and only four (12\%) cases comprised malignant tumor adenocarcinoma of stomach. Two of the cases of chronic gastritis also showed H.Pylori organism on Giemsa stain (Figure 2). Colonoscopy biopsies received during time period of study comprised of 29 cases. (Table 5) Out of which $18(62.07 \%)$ were male and 11 (37.93\%) were female. Twenty-seven (93\%) were benign and inflammatory lesions and two (7\%) were malignant tumors revealing adenocarcinoma of rectum. Most of the cases 22 (76\%) were from colon and seven cases (24\%) were from rectum. Most of the cases were of Inflammatory bowel disease (IBD). Out of total 18 cases of IBD six showed histologic features of Crohn's (CD) disease (Figure 3) and the other five showed histologic features of Ulcerative Colitis (UC). Rest of the seven cases of IBD on histologic examination could not be categorized specifically as UC or CD. In such cases a repeat biopsy sample was advised. Only $7 \%$ of the cases were of malignant tumor comprising of adenocarcinoma of rectum. Total 16 oral biopsy tissues were received. Out of which $12(75 \%)$ were male and 4 (25\%) were female. Inflammatory and benign lesion comprised of $15(94 \%)$. Commonest lesion was mucocele which comprised a total of $08(50 \%)$ cases. One $(6 \%)$ case was malignant tumor squamous cell carcinoma of the tongue. (Table 6).

Ten surgical resected tissues were received from various organs of GIT. (Table7). There was one resected biopsy of rectal mass measuring $9 \mathrm{~cm}$ in maximum diameterin a35 year old female patient (Figure 4) which showed Mucinous adenocarcinoma on microscopy examination(Figure 5)and one resected tissue of colonic mass in a 30 year old male was received which showed histologic features of submucosal Lipoma (Figure 6).One pancreatic tissue of female patient aged 20 years old reveal histologic features of Chronic Pancreatitis and one case was of a Simple Hepatic Cyst of the liver. Cyst measured $3 \times 2 \times 1 \mathrm{~cm}$ and the patient was a 60 year old female. Three biopsies were of hemorrhoids and three biopsies were from the Fistula in Ano all were male patients. The fistulous tract histologically was surrounded by granulation tissue.

Table 2: Distribution of (160) lesions of Gallbladder
according to histopathology
\begin{tabular}{|l|c|c|l|}
\hline Histopathology & Male & Female & No. of cases (\%) \\
\hline Chronic cholecystitis & 22 & 83 & $105(65.5 \%)$ \\
\hline $\begin{array}{l}\text { Chronic cholecystitis with } \\
\text { cholesterolsis }\end{array}$ & 10 & 34 & $44(27.5 \%)$ \\
\hline Xanthogranulomatous cholecystitis & 2 & & $2(1.25 \%)$ \\
\hline Cholesterol polyps with cholecystitis & 1 & 2 & $3(2 \%)$ \\
\hline Acute on chronic cholecystitis & & 2 & $2(1.25 \%)$ \\
\hline $\begin{array}{l}\text { Low grade biliary intraepithelial } \\
\text { Neoplasia (BIN) }\end{array}$ & 2 & 1 & $3(2 \%)$ \\
\hline Adenocarcinoma & 1 & & $1(0.5 \%)$ \\
\hline
\end{tabular}

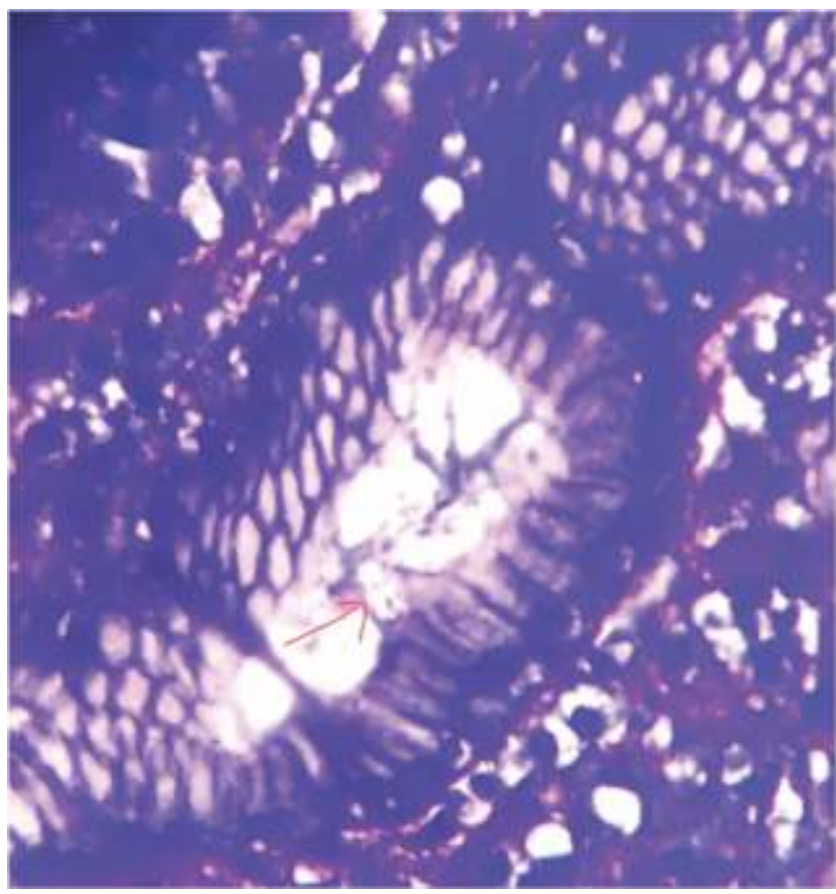

Figure 2: Picture showing H-pylori in Giemsa stain (100X). 


Table 3: Distribution of (95) lesions of appendix according
to histopathology
\begin{tabular}{|l|c|c|c|}
\hline Histopathology & Male & Female & $\begin{array}{c}\text { No of } \\
\text { cases }(\%)\end{array}$ \\
\hline Acute Suppurative Appendicitis & 25 & 25 & $50(52 \%)$ \\
\hline Acute Appendicitis & 17 & 13 & $30(32 \%)$ \\
\hline $\begin{array}{l}\text { Gangrenous/necrotizing } \\
\text { appendicitis }\end{array}$ & 7 & 4 & $11(12 \%)$ \\
\hline Eosinophilic appendicitis & 2 & 2 & $4(4 \%)$ \\
\hline
\end{tabular}

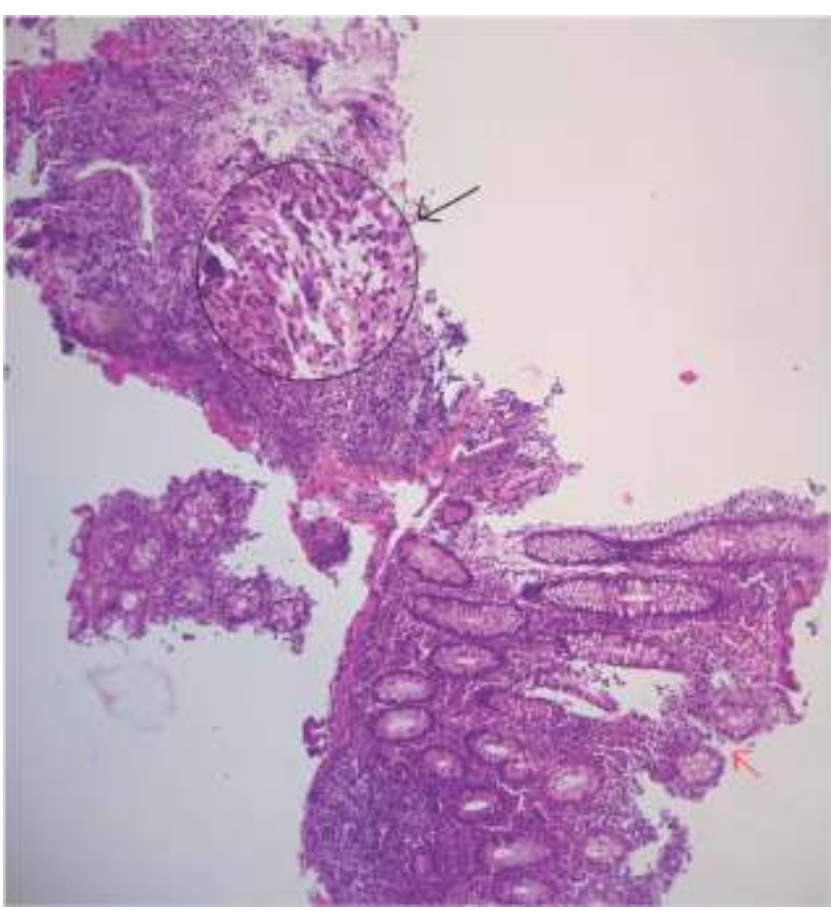

Figure 3: H\&E stain revealing epithelioid cell granuloma in Crohn's disease (10X)

Table 4: Distribution of (34) lesions of endoscopy biopsy
according to histopathology
\begin{tabular}{|l|c|c|r|}
\hline Histopathology & Male & Female & No. of cases $(\%)$ \\
\hline Chronic Mild Active Gastritis & 5 & 4 & $09(26 \%)$ \\
\hline Chronic Moderate Active Gastritis & 9 & 6 & $15(44 \%)$ \\
\hline Adenocarcinoma stomach & 3 & 1 & $4(12 \%)$ \\
\hline Gastric hyperplastic polyp & 1 & 1 & $2(6 \%)$ \\
\hline Peptic duodenitis & 1 & 1 & $2(6 \%)$ \\
\hline Peptic Ulcer & 1 & & $1(3 \%)$ \\
\hline Oesophaguscandiasis & 1 & & $1(3 \%)$ \\
\hline
\end{tabular}

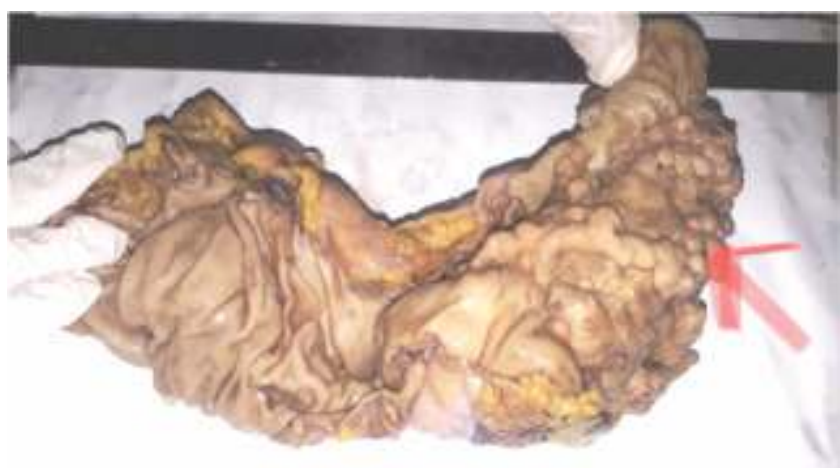

Figure 4: Gross Picture of a resected specimen of rectum tissue showing grey brown irregular nodular growth near one end.

Table 5: Distribution of (29) lesions of colonoscopy biopsy
according to histopathology
\begin{tabular}{|l|c|c|r|}
\hline Histopathology & Male & Female & $\begin{array}{c}\text { No of } \\
\text { cases }(\%)\end{array}$ \\
\hline Inflammatory Bowel Disease & 10 & 8 & $18(62 \%)$ \\
\hline Adenocarcinoma Rectum & 1 & 1 & $2(7 \%)$ \\
\hline Inflammatory rectal polyp & 2 & 1 & $3(10 \%)$ \\
\hline Hyperplastic rectal polyp & 1 & 1 & $2(7 \%)$ \\
\hline Melanosis coli & 1 & & $1(3.5 \%)$ \\
\hline Juvenile rectal polyp & 1 & & $1(3.5 \%)$ \\
\hline Focal proctitis & 2 & & $2(7 \%)$ \\
\hline
\end{tabular}

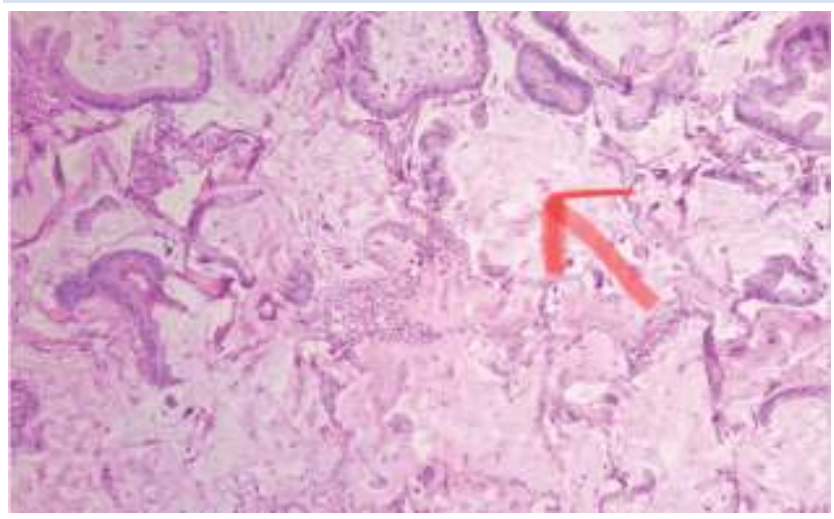

Figure 5: H\&E stain showing Mucinous adenocarcinoma of Rectum with abundant mucin pool(X20X)

Table 6: Distribution of (16) lesions of oral biopsy according to histopathology

\begin{tabular}{|l|c|c|r|}
\hline Histopathology & Male & Female & $\begin{array}{r}\text { No. of } \\
\text { cases (\%) }\end{array}$ \\
\hline Oral Mucocele & 5 & 3 & $8(50 \%)$ \\
\hline Chronic Tonsillitis & 3 & & $3(19 \%)$ \\
\hline Oral Fibroma & 2 & 1 & $3(19 \%)$ \\
\hline Radicular Cyst & 1 & & $1(6 \%)$ \\
\hline $\begin{array}{l}\text { Squamous cell } \\
\text { carcinoma tongue }\end{array}$ & 1 & & $1(6 \%)$ \\
\hline
\end{tabular}

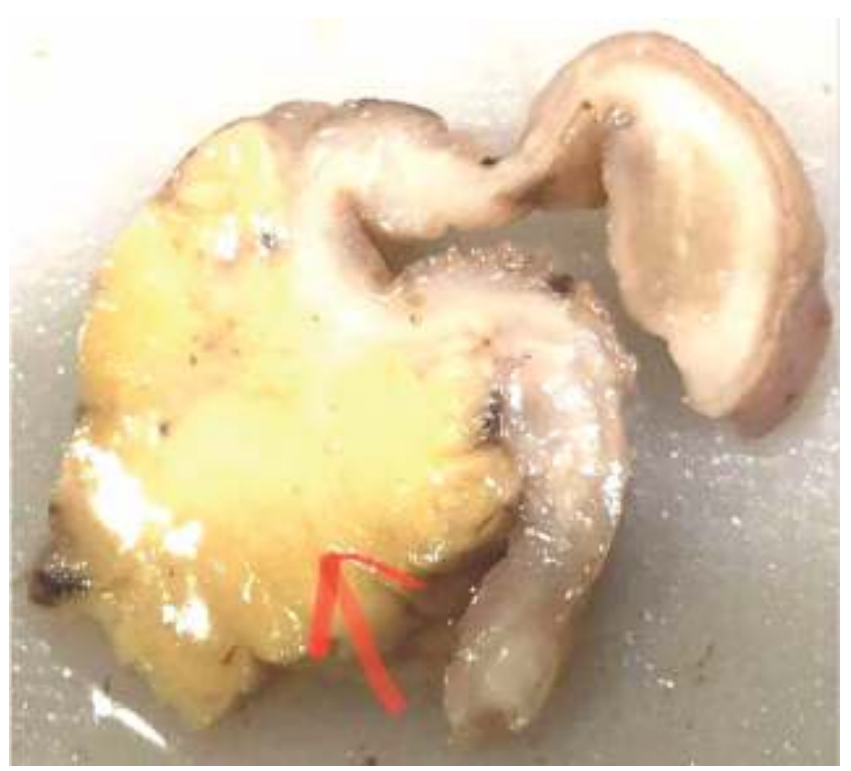

Figure 6: Gross Picture showing a resected large bowel tissue showing grey yellow submucosalLipoma

\begin{tabular}{rrr} 
& Birat Journal of Health Sciences \\
\hline 15032 & ISSN: 2542-2758 (Print) 2542-2804 (Online) & Vol.6/No.2/Issue 15/May-Aug., 2021
\end{tabular}


Table 7: Distribution of (10) lesions of GIT according to histopathology

\begin{tabular}{|l|c|c|r|}
\hline Histopathology & Male & Female & \multicolumn{1}{|c|}{$\begin{array}{c}\text { No. of } \\
\text { cases (\%) }\end{array}$} \\
\hline Adenocarcinoma Rectum & & 1 & $1(10 \%)$ \\
\hline Submucosal lipoma of colon & & 1 & $1(10 \%)$ \\
\hline Chronic Pancreatitis & & 1 & $1(10 \%)$ \\
\hline Simple Hepatic Cyst & & 1 & $1(10 \%)$ \\
\hline Hemorrhoids & 3 & & $3(30 \%)$ \\
\hline Fistula in Ano & 3 & & $3(30 \%)$ \\
\hline
\end{tabular}

\section{DISCUSSION}

Gallbladder disease chronic cholecystitis because of gall stones was the most common lesion in our study. Chronic cholecystitis because of cholesterol gall stones are increasing in Nepal because of a sedentary lifestyle, obesity, diabetes and a non-vegetarian diet. ${ }^{6}$ We know from previous studies that risk of gall stones are 4 times more in people above 40 years as compared to young people. ${ }^{7}$ We found in our study that $105(65 \%)$ of our patients with gall stone disease were above 40 years of age. In our study $122(78 \%)$ of gall bladder disease were in female gender. Searching the literature also shows that female sex develops gallstones more commonly than men. ${ }^{8}$

Acute appendicitis is more common during first and the second decade of life. ${ }^{9}$ We found in our study that $38(42 \%)$ of patients of acute appendicitis were between 1-20 years of age. In total 90 cases of appendix tissue were received we did not find any malignant tumor. This finding is in correlation with various other studies which also show that cancers of appendix are rare..$^{10}$

In our study out of 24 cases of confirming gastritis on histologic examination, we could demonstrate only two cases confirming H Pylori organism on Giemsa stain. H Pylori has been associated with tissue damage in patients with active and chronic gastritis. ${ }^{11} \mathrm{H}$ Pylori organism is also the major cause of chronic gastritis. ${ }^{12}$ In underdeveloped countries detection of this organism is not so common because it causes patchy involvement of gastric mucosa. ${ }^{13}$

Gastroenterologist generally performs a colonoscopy biopsy to diagnose inflammatory bowel disease (IBD) i.e. ulcerative colitis or Crohn's disease. Sixty two percent of cases of colonoscopy biopsy in our study showed histologic features of IBD. IBD can be diagnosed on combinations of various tests which comprises of imaging, endoscopy and histopathology. In our study seven cases of IBD on colonoscopy biopsy could not be categorized on histopathology examination. Such cases need either repeat biopsy sample or should be correlated with other modalities like imaging, clinical picture or endoscopy features. Mucocele was the most common oral lesion in our study in which there is mucin spillage in soft tissue. It is a swelling caused because of pooling of saliva. ${ }^{14}$ Histopathologic examination of the tissue is done for confirmation of diagnosis and to rule out neoplasia. ${ }^{15}$ We found all the excised tissue of Mucus cyst consistent with Mucocele and none of them reveal malignancy. We found only one cystic lesion of liver that was a simple hepatic cyst. Various studies have also shown that cystic lesions of the gastrointestinal tract are not common and most of the lesions are benign. ${ }^{16}$ Most common malignant tumor in our study was adenocarcinoma. This finding was similar to study done by Sharma et al and Lavanya et al. ${ }^{17,18}$ Commonest site of cancer in our study were stomach followed by rectum. Study conducted by Shah et al showed that consumption of heavy amount of oil/fat, processed meat and salt in Nepalese people are few of the risk factors for development of gastric carcinoma. ${ }^{19}$

Study done by Shrestha et al revealed that among the top ten cancers in Nepal, carcinoma stomach stands in $4^{\text {th }}$ place and colorectal carcinoma in $5^{\text {th }}$ place ${ }^{20}$. We also saw that after gastric cancer second common cancer was carcinoma of the rectum.

\section{CONCLUSIONS}

The study identifies that gastrointestinal lesions are common and comprise of the most common biopsies received in the histopathology department. Histopathologic examinations are necessary for the early diagnosis of the GI disease. Most of the GI lesions are benign. The commonest lesion occurring in GIT is Chronic Cholecystitis because of gallstones disease. Acute Appendicitis is the commonest lesion occurring in the younger age group of 1-20 years. Malignant lesions are less common. Early diagnosis of premalignant and malignant lesions can help the treating doctor and can increase the overall survival rate of patients by maintaining a good quality of life.

\section{RECOMMENDATIONS}

All the surgically resected GIT tissue must be submitted for histopathologic examination. Early detection of lesions may prevent the disease from further progression.

\section{LIMITATION OF THE STUDY}

The study was conducted in a short period. If we would have studied for longer duration the data of our study could have been more authentic. Immunohistochemistry is must especially in the categorization of malignant lesions. In the study we have not applied Immunohistochemistry. If we could have applied Immunohistochemistry we could have been more confident in our diagnosis. Sometimes especially in endoscopy and colonoscopy biopsies the tissue submitted may be from the edge of the lesion and may not be the true representative of the lesion. In such cases biopsy report may not be true representative of the disease. Comparison of biopsy report with endoscopy and colonoscopy findings along with radiologic data should be done. If there is suspicion of malignancy a repeat biopsy sample should be submitted.

\section{ACKNOWLEDGEMENT}

The author will like to thank all the laboratory staff of the histopathology department of BMCTH for their support.

\section{CONFLICT OF INTEREST}

None

\section{FINANCIALDISCLOSURE}

None 


\section{REFERENCES}

1. Thakur $R$ Y, Nikumbh D B, Swami $S Y$, Clinico Histopathological Overview of GIT Lesions in a Rural Hospital. Indian J Pathol Oncol 2016;3(2):305-314 https://www.ijpo.co.in.

2. Amrish Kumar, Vrish Dhwaj Ashwlayan, Mansi Verma, Vipin Kumar Garg, Anurag, Anjana Sharma, Sameksha Koul, Avnish Kumar Singh, Nitin Sharma, Anoop Kumar, Anuj Kumar, Garima Garg, Shobhit Kumar, Sachin kumar, Nishant Kumar and Satish Kumar Gupta. Investigation on Gastrointestinal Tract: A Review. Doi 10.32474/ LOJMS.2018.01.000116

3. Neha MukeshGoel, Abhay Y Desai, WaghmareRohan Mohan, Vijay D Dombale. A study of histopathological spectrum of gastrointestinal tract lesions in a rural tertiary care centre. MedPulse International Journal of Pathology. December 2019; 12(3): 153-160. DOI: https:// doi.org/10.26611/1051238

4. World Health Organization (WHO), "World Health Organization Cancer Country Profiles, Nepal," 2014, https://www.who.int/ cancer/ country-profiles/npl_en.pdf?ua=1.

5. Minami H. Isomoto H.Inoue H. Akazawa Y. Yamaguchi N. OhnitaK.Takeshima F. Hayashi T. Nakayama T. Nakao K. Significance of Background Coloration in Endoscopic Detection of Early Esophageal Squamous Cell Carcinoma Digestion 2014;89:6-11 https://doi.org/10.1159/000356200

6. Neupane P Ram, Tirtha M Shrestha, Shankar Raut, Ramesh P Aacharya Risk Factors for Gall Stone Diseases in Patients Presenting to General Practice Out Patient Department in a Tertiary Care Center in Nepal .JIOM Nepal, Volume 41, Number 2, August 2019, page 2629 DOI: https://doi.org/10.3126/jiom.v41i2.26545

7. Barbara L, Sama C, MorselliLabate AM, et al. A population study on the prevalence of gallstone disease: the Sirmione Study. Hepatology 1987; 7(5):913-917. doi:10.1002/hep.1840070520

8. Sood S, Winn T, Ibrahim S, Gobindram A, Arumugam AA, Razali NC, Yasmin P, Hidayu N, Sani H, Mustafa MH, Fatinah A, Devi A, Karim AA, Obaid KJ, Haron NH, Fitjerald H, Koshy M. Natural history of asymptomatic gallstones: differential behaviour in male and female subjects. Med J Malaysia. 2015 Dec; 70(6):341-5. PMID: 26988206.

9. Marzuillo P, Germani C, Krauss BS, Barbi E. Appendicitis in children less than five years old: A challenge for the general practitioner.World J ClinPediatr. 2015;4:19-24. doi: 10.5409/wjcp.v4.i2.19

10. ZulfuBayhan, YasinAlperYildiz, YesimAkdeniz, EmreGonullu, Fatih Altintoprak, BarisMantoglu, RecayiCapoglu, Zeynep Kahyaoglu Akkaya, "Appendix Neuroendocrine Tumor: Retrospective Analysis of 4026.Appendectomy Patients in a Single Center", Emergency Medicine International, vol. 2020, Article ID 4030527, 6 pages, 2020. https://doi.org/10.1155/2020/4030527
11. Johnson KS, Ottemann KM. Colonization, localization, and inflammation: the roles of $\mathrm{H}$. pylori chemotaxis in vivo. CurrOpin Microbiol. 2018 Feb;41:51-57. doi: 10.1016/j.mib.2017.11.019. Epub 2017 Dec 1. PMID: 29202336; PMCID: PMC5862749.

12. Mohamed M. Elseweidy (January 16th 2013). Helicobacter Pylori Infection and Its Relevant to Chronic Gastritis, Current Topics in Gastritis - 2012, GyulaMozsik, IntechOpen, DOI: 10.5772/52276.

13. Sharma P, KauKK, MahajanM, Gupta P. Histopathological spectrum ofvarious gastro-duodenal lesions in North India and prevalence of Helicobacter pylori infection in these lesions: a prospective study. Int J Res MedSci. 2015;3(5):1236-41. DOI: 10.5455/2320-6012.jjrms 20150536

14. Garcia-León, N., \&Marrugo, G. E. (2013). Mucocele of the glands of blandinnuhn: a case report. Colombia Médica, 44(1), 46-47. https:// doi.org/10.25100/cm.v44i1.841

15. More CB, Bhavsar K, Varma S, Tailor M. Oral mucocele: A clinical and histopathological study. J Oral Maxillofac Pathol. 2014 Sep;18 (Suppl 1): S72-7. doi: 10.4103/0973-029X.141370. PMID: 25364184; PMCID: PMC4211243.

16. Jongmee Lee, Cheol Min Park, Kyeong Ah Kim, Chang Hee Lee, Jae Woong Choi, Bong Kyung Shin, Soon Jin Lee, Dongil Choi, Kee-Taek Jang Cystic Lesions of the Gastrointestinal Tract: Multimodality Imaging with Pathologic Correlations Korean J Radiol. 2010 Jul-Aug; 11(4): 457-468. P21. doi: 10.3348/kjr.2010.11.4.457

17. Sharma PP, Patel NB, Parmar UM. Histopathological Study of Gastrointestinal Tumors. Int J Sci Stud 2018;6(4):23-25. DOI: 10.17354/ijss/2018/198

18. Lavanya M, Sreelatha R. Histopathological Study of Tumours of Stomach and Intestines. Rajiv Gandhi University of Health Sciences, Karnataka, Bangalore; April 2010. DOI: 10.17354/ijss/2018/198

19. Sunil Kumar Shah, Dev Ram Sunuwar, Narendra Kumar Chaudhary, PushpaRai, Pranil Man Singh Pradhan, Narayan Subedi, Madhu Dixit Devkota, "Dietary Risk Factors Associated with Development of Gastric Cancer in Nepal: A Hospital-Based Case-Control Study", Gastroenterology Research and Practice, vol. 2020, Article ID 5202946, 8 pages, 2020. https://doi.org/10.1155/2020/5202946

20. Gambhir Shrestha, Prakash Neupane, Nirmal Lamichhane ,Bijaya Chandra Acharya, Bhola Siwakoti, Krishna Prasad Subedi, Kishore Kumar Pradhananga, Rashmi Mulmi Cancer Incidence in Nepal: A Three-Year Trend Analysis 2013-2015 DOI 10.31557/ apjcc. 2020.5.3.145-150. 